\title{
What's being used at home: a household pesticide survey
}

\author{
Judith K. Bass, ${ }^{1}$ Luis Ortega, $^{2}$ Cecilia Rosales, ${ }^{2}$ \\ Norman J. Petersen, ${ }^{2}$ and Rossanne M. Philen ${ }^{1}$
}

ASTRACT Objective. Since very little is known about the health effects that household pesticides have on children, we conducted this survey to identify what pesticides are being used in the home, where they are being used and stored, and what methods are used for their disposal.

Methods. In the spring of 1999 we conducted a survey in a community in the state of Arizona, in the United States of America, on the border with Mexico. To be eligible to participate in the survey, households had to have used a pesticide in the 6 mo prior to the survey and to have at least one child under the age of 10 years. We gathered general information on pesticide usage, storage, and disposal, in addition to specific information about each of the pesticides currently being used and/or stored in the home.

Results. In the 107 households surveyed, we found 148 pesticide products, for a mean of 1.4 per household. Half of the pesticides were stored less than 4 feet $(1.22 \mathrm{~m})$ from the ground, at a level a child could reach. Seventy percent of all the pesticides were stored inside the home, with the kitchen being the storage room most often mentioned. The kitchen was also the room where most of the pesticides were used, with $69 \%$ of the respondents saying they had used at least one pesticide there.

Conclusions. From our research we conclude that it will be important to continue to investigate all avenues of pesticide exposure in order to fully evaluate childhood exposures. Understanding household pesticide use and developing a model of exposure will help in this process. Profiles of the use, storage, and disposal of products will also guide the development of effective education and poison prevention programs in the community.

Key words Pesticides, health of children, United States of America, health surveys, household products.

Pesticides are used in $85 \%$ to $90 \%$ of the households in the United States of America (1). Currently, very little is known about the extent or the effects

\footnotetext{
United States, Centers for Disease Control and Prevention, National Center for Environmental Health, Atlanta, Georgia, United States of America. Address correspondence to: Judith Bass and Rossanne Philen, Centers for Disease Control and Prevention, National Center for Environmental Health, Health Studies Branch, 1600 Clifton Road NE (Mailstop E-23), Atlanta, Georgia 30333, United States of America.

2 Arizona Department of Health Services, Tucson, Arizona, United States of America.
}

of exposure to household pesticides on the health and development of children in the households that use them. Young children are especially vulnerable to exposure in the home, and they may be exposed in various ways, including inhalation, absorption through skin contact, ingestion during food consumption, or accidental ingestion of the pesticide itself, often from handto-mouth contact after exposure $(2,3)$. In addition, the physiological vulnerability of children differs from that of adults because pound for pound of body weight, children breathe more, eat more, and have a more rapid metabolism than adults do (4).

Previous studies have examined a variety of sources of exposure, including pesticide drift, take-home exposure from family members working in agriculture, and exposures at schools and playgrounds near treated land (5, 6). These studies have shown that high levels of pesticide exposure can lead to many short- and long-term health effects $(5,7)$. Though studies have been conducted that examine some aspects 
of household pesticide use and childhood exposure (8-12), very few have comprehensively examined the exposure potential for children in the home.

The purpose of this study was to develop an inventory and description of household pesticide use in a community in the United States of America that is on the border with Mexico, and to examine potential routes of exposure for young children living in those homes.

\section{METHODS}

\section{Study design}

We assessed household pesticide use by a community-based survey conducted in March 1999. We made telephone calls and conducted interviews within a one-week period. The study population consisted of all households in the community of Douglas, Arizona, a town that was selected specifically because it is a nonagricultural area; agricultural pesticides are not addressed in this study.

\section{Study participants}

We conducted a systematic random sampling to choose study participants. Using a residential phone book, we gave lay health workers (promotoras) a list of approximately 200 names (five or six pages from the phone book) of possible participants to contact, determine eligibility, and set up interview appointments with. The health workers were community members who were recruited to help with this study because of their interest in community health issues. They were paid specifically for work they did with this study on a per-interview basis. The health workers were instructed to start with the first name on their list and call every fifth name; when they reached the end of their list, they returned to the second name on the list and continued on following the same pattern. Nine health workers and one super- visor were trained by the project researchers on how to make phone calls, set up interviews, and conduct the survey. The local supervisor was trained to help the research staff deal with local inquiries and problems that might arise in carrying out the study. Of these 10 persons, the supervisor and eight of the health workers actually participated in the study.

Eligibility for study participation was based on the respondent having used at least one pesticide at home (household pesticide was defined during the initial phone call) in the $6 \mathrm{mo}$ prior to the survey, and having a child under the age of 10 years living in the home.

\section{Household survey}

We assessed pesticide use by a oneon-one interview, conducted by the health workers, in the participant's home. During the initial telephone contact, the health worker had asked to interview the person in the household most likely to know about household pesticide use. The term "household pesticide" was defined for the study respondents as any product used in or around the home for cockroaches, insects, termites, rats and other rodents, fleas and ticks, and weeds in the garden, as well as to keep animals away from the garden or yard.

During the in-home interviews, the health workers asked the respondents to show them all of the products they used for pest control. The health workers collected information about each product, including location of use (including which rooms), frequency of use, pesticide concentration, form of pesticide applied (e.g., aerosol spray, pellet, powder, etc.), purpose of application (i.e., target pests), mode of application, and area covered by application. We also collected information about the use of the pesticides by the respondent and other household members, treatment by outside companies, and pesticide disposal methods.

For each labeled pesticide, the health workers recorded the active ingredients and the registration number the product had been given by the United States Environmental Protection Agency (EPA). The health workers were asked to take samples of any product found without labeling, either because the label was illegible or the product was not in its original container. Following an established proto$\mathrm{col}$, these unlabeled-product samples were transported to the laboratories of the United States Centers for Disease Control and Prevention (CDC) in Atlanta, Georgia, for content analysis. Two samples of unlabeled products were taken.

\section{Analysis}

We used EPA registration numbers, product name, and active ingredients lists to confirm the brand and name of each pesticide. In addition, for general product and active-ingredients identification purposes we used the Internet site of the California Department of Pesticide Regulation (http:// www.cdpr.ca.gov) and the EPA Pesticide Product Label System, a software product on CD-ROM that contains images of registered pesticide product labels submitted to the EPA Office of Pesticide Programs. To assign toxicity rankings for each of the active ingredients, we used the 1998 edition of the Farm Chemicals Handbook (13).

We conducted analyses based on four toxicity classes of the active ingredients and also on signal words (danger, warning, and caution) on the pesticide products themselves. We calculated descriptive statistics using SPSS 9.0 software (SPSS Inc., Chicago, Illinois, United States of America).

\section{RESULTS}

The health workers made a total of 986 telephone calls. Approximately one-fourth of the numbers called were for nonresidential locations, had been disconnected, or were not answered. Another $30 \%$ of the calls made went to households that did not meet eligi- 
bility requirements. Of the 141 eligible contacted households, 107 successfully completed interviews with participants who met the inclusion criteria, for a participation rate of $75.9 \%$.

Of the 107 respondents, 90 of them $(84 \%)$ were female. The majority of the respondents (89\%) self-identified as Hispanic, with 72 (67\%) of the respondents preferring the interviews be conducted in Spanish. Other demographic characteristics of the respondents are shown in Table 1.

\section{General pesticide use survey}

All of the study participants had used pesticides in the 6 mo prior to the survey, with $75 \%$ reporting pest problems during the same time period. Roaches and ants were the most frequently reported pests. Nearly $40 \%$ of respondents reported having weed problems for which they used pesticides.

Over a third of the respondents indicated use of a professional exterminator in the 6 mo prior to the survey. None of them knew what chemicals the exterminators had applied.

Nearly two-thirds of the households had only one pesticide in their home at the time of the survey. Six of the households $(5.6 \%)$ had three or more products, with two of these participants reporting having seven pesticide products in the home. The mean number of pesticide products per home was 1.4.

\section{Survey of the specific pesticides}

A total of 148 pesticide products were found in the 107 surveyed households (Table 2). These 148 products represented more than 50 specific commercial pesticides. Forty-seven (32\%) of the pesticide products were used once a week or more, with another $42(28 \%)$ used once a month.

The majority of the pesticides $(70 \%)$ were stored inside the house (excluding the basement), with the kitchen being the most often used storage room $(45 \%)$ (Table 2). Fifty-six percent of the products were in child-resistant containers. About a third of all the products were kept in a locked storage area. Nearly $50 \%$ of the households stored their pesticides less than four feet $(1.22 \mathrm{~m})$ from the ground, a height accessible to young children.

Few of the pesticides $(11 \%)$ had been in the home for more than $24 \mathrm{mo}$, with most being brought into the home in the year prior to the survey (Table 2). Nearly all of the products were obtained in the United States; 7\% came from Mexico. Additional details on pesticide storage and use are shown in Table 2.

Pesticide products were used both inside the house and also outside the home, such as in the yard and around the foundation. Approximately $70 \%$ of the respondents said they had used the pesticide in the kitchen and nearly $55 \%$ had used it in the bathroom. In addition, nearly $60 \%$ of the respondents reported having used the product outside (data not shown).

Participants were asked in which rooms they used the pesticide products. Figure 1 shows the number of pesticides used in each room. Each pesticide could be used in more than one room of the home, as well as outside the house.

Inside the house the most common sites of application were the floors $(55 \%)$ and baseboards (33\%). Sixteen percent of the pesticides were used in cupboards with dishes or cookware, and $12 \%$ were used in cupboards where food was stored. Many of the pesticide products were used in multiple locations and multiple rooms, as well as outside the house.

TABLE 1. Demographic characteristics of participants, household pesticide survey, Arizona, 1999 (107 households surveyed)

\begin{tabular}{|c|c|c|}
\hline Characteristic & No. $^{a}$ & $\%^{a}$ \\
\hline \multicolumn{3}{|l|}{ Respondent gender } \\
\hline Female & 90 & 84.1 \\
\hline Male & 17 & 15.9 \\
\hline \multicolumn{3}{|l|}{ Language of interview } \\
\hline Spanish & 72 & 67.3 \\
\hline English & 35 & 32.7 \\
\hline \multicolumn{3}{|l|}{ Reading skills } \\
\hline Able to read English & 71 & 66.4 \\
\hline Able to read Spanish & 95 & 88.8 \\
\hline \multicolumn{3}{|l|}{ Number in household } \\
\hline 2-3 people & 25 & 23.3 \\
\hline 4-5 people & 59 & 55.1 \\
\hline 6-8 people & 23 & 21.4 \\
\hline \multicolumn{3}{|l|}{ Children under age 10} \\
\hline 1 child & 37 & 34.6 \\
\hline 2 children & 45 & 42.1 \\
\hline 3-5 children & 25 & 23.3 \\
\hline \multicolumn{3}{|l|}{ Type of home } \\
\hline Single-family detached & 75 & 70.1 \\
\hline Multifamily & 9 & 8.4 \\
\hline Trailer/mobile home & 9 & 8.4 \\
\hline Single-family attached & 8 & 7.5 \\
\hline Apartment/other & 4 & 3.7 \\
\hline \multicolumn{3}{|l|}{ Window screens } \\
\hline On all of the windows & 84 & 78.5 \\
\hline On some of the windows & 15 & 14.0 \\
\hline On none of the windows & 6 & 5.6 \\
\hline \multicolumn{3}{|l|}{ Pets } \\
\hline Pets kept in the household & 55 & 51.4 \\
\hline Pesticides used on pets & 22 & 40.0 \\
\hline
\end{tabular}


TABLE 2. Household pesticide types and characteristics, household pesticide survey, Arizona, 1999 (148 individual pesticide products found)

\begin{tabular}{|c|c|c|}
\hline & No. ${ }^{a}$ & $\%^{a}$ \\
\hline \multicolumn{3}{|l|}{ Type of pesticide } \\
\hline Insecticide & 135 & 91.2 \\
\hline Rodenticide & 10 & 6.8 \\
\hline Herbicide & 3 & 2.0 \\
\hline \multicolumn{3}{|l|}{ Storage of pesticide } \\
\hline Kitchen & 67 & 45.3 \\
\hline Garage/Shed & 30 & 20.3 \\
\hline Laundry room/Washroom & 14 & 9.4 \\
\hline Other - inside the home & 11 & 7.4 \\
\hline Other — outside the home & 7 & 4.7 \\
\hline Bathroom & 7 & 4.7 \\
\hline Basement & 4 & 2.7 \\
\hline Closet & 4 & 2.7 \\
\hline \multicolumn{3}{|l|}{ Storage precautions } \\
\hline Child-resistant container & 83 & 56.1 \\
\hline Pesticide locked away & 55 & 37.2 \\
\hline \multicolumn{3}{|l|}{ Storage risks } \\
\hline \multicolumn{3}{|l|}{ Stored less than 4 feet } \\
\hline from the ground & 72 & 48.6 \\
\hline Kept near food & 5 & 3.4 \\
\hline Kept near dishes/cookware & 5 & 3.4 \\
\hline \multicolumn{3}{|l|}{ Disposal } \\
\hline Throw it away & 132 & 89.2 \\
\hline \multicolumn{3}{|l|}{ Wrap in separate container } \\
\hline before throwing away & 10 & 6.8 \\
\hline Other & 5 & 3.4 \\
\hline \multicolumn{3}{|l|}{ Frequency of use } \\
\hline More than once per wk & 20 & 13.5 \\
\hline Once per wk & 27 & 18.2 \\
\hline Once per mo & 42 & 28.4 \\
\hline Once every 3 mo & 23 & 15.5 \\
\hline Once every 6 mo & 16 & 10.8 \\
\hline Once per yr & 13 & 8.8 \\
\hline \multicolumn{3}{|l|}{ Time stored in the home } \\
\hline Less than 6 mo & 75 & 50.7 \\
\hline $6-12 \mathrm{mo}$ & 24 & 16.2 \\
\hline $12-24 \mathrm{mo}$ & 17 & 11.5 \\
\hline More than $24 \mathrm{mo}$ & 16 & 10.8 \\
\hline
\end{tabular}

a Totals may not add to 148 products or to $100 \%$ due to some nonresponses to survey questions.

Participants were also asked about the locations within the rooms where they used the pesticide products. Figure 2 shows the number of times a particular location within the rooms or in an area outside the house was sited as being one where each of the 148 pesticide products was used; each pesticide could be used in more than one location.

Thirty-seven active ingredients were identified from the 50 different commercial pesticides. Table 3 lists these ingredients in order of the number of times we found them. Each pesticide could have more than one active ingre- dient. Technical piperonyl butoxide, a synergist often used to slow the enzymatic degradation of various pesticides (14), was the most common ingredient and was found in $23 \%$ of the 148 products. Other active ingredients (in descending order of frequency) included pyrethrins $(16 \%)$, permethrin $(12 \%)$, d-cis, trans allethrin $(11 \%)$, diazinon (11\%), and boric acid (9\%).

Five of the active ingredients were rated as class I chemicals, or highly toxic. These five chemicals were in 21 $(14 \%)$ of the pesticide products found in the homes. There were no statistically significant differences in toxicity levels by place of storage or frequency of use of the different pesticides. One of the highly toxic chemicals, EPN, is currently banned by the EPA. In addition, a product from China called "Miraculous Insecticide Chalk," also banned by the EPA, was found in seven homes. Toxicity class ratings for the active ingredients are listed in Table 3.

\section{DISCUSSION}

We conducted this survey to begin to answer some of the questions raised in other studies and to strengthen the general knowledge of household pesticide use and potential human exposure, especially in children. This survey was conducted in an Arizona town on the border with Mexico, with relatively low-income Hispanic persons, a population often overlooked both in research in general and in public health initiatives. The results of this survey show that many, but not all, of the issues from other household pesticide surveys $(8,10)$ are applicable to this population as well. In comparison, this population uses fewer pesticides per household as well as different pesticides from those found in other studies.

The results of this survey agree with other studies that, in general, household pesticide use does not appear to present a significant exposure hazard. However, in the United States the majority of persons, especially children, are exposed to pesticide products through multiple routes, in-home exposure being only one of many. Thus, understanding and being able to measure exposures to household pesticides is just one piece of the puzzle in completely defining pesticide exposure.

All of the respondents had used a pesticide in the 6 mo prior to the survey, but only $75 \%$ of the participants reported having pest problems during that same period. This finding may suggest that some people are using pesticides for preventive purposes, which may not be their intended use. 
FIGURE 1. Number of times specific rooms were mentioned for pesticide use in and around the home, household pesticide survey, Arizona, 1999 (148 pesticide products) ${ }^{\mathrm{a}}$

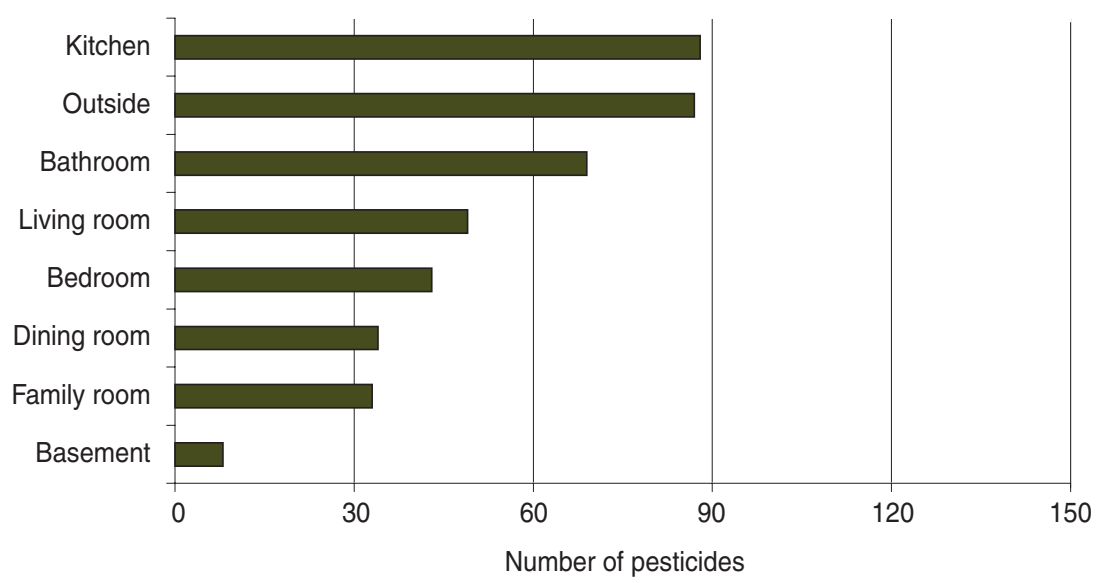

a Each pesticide could be used in more than one room.

In addition, the respondents said they used the pesticides throughout their homes. While it is not possible to know from this survey whether all the pesticides are being used safely and properly, this is an important concern. An Australian rodenticide poisoning study found that $69 \%$ of their study respondents believed that the site where they put out the poison would not normally allow access to children (15). In addition, the fact that the kitchen is a major location for pesticide application raises concerns over pesticide exposure through food contamination or food preparation.

The mean quantity of products per household was 1.4, slightly lower than

FIGURE 2. Number of times specific locations were mentioned for pesticide application in and around the home, household pesticide survey, Arizona, 1999 (148 pesticide products) $)^{\mathrm{a}}$

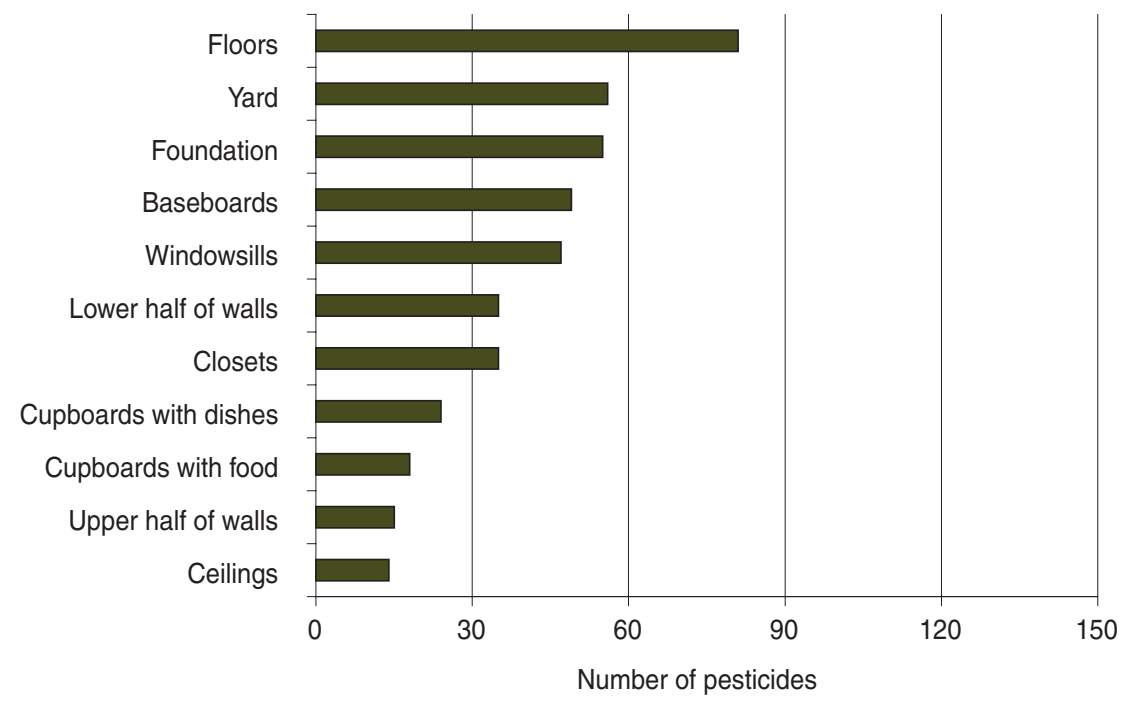

a Each pesticide could be used in more than one location.

the amount found in other studies (8-10). However, in the 107 households interviewed, we found more than 50 different commercial pesticides, with over half showing up only once. This finding makes it particularly important for researchers and policy makers to identify the active ingredients in the products in order to understand the potential chemical exposures. It is not enough just to know the brand names of the products, since that does not provide information about the type and quantity of active ingredients.

Many of the identified active ingredients that we found in our survey have low toxicity ratings. That may indicate that people in the households where the pesticides are used are at low risk for adverse health outcomes; however, all pesticides are innately toxic. Accidental ingestion of any one of them can potentially poison a child. In addition, very little is known about the synergistic effect of multiple exposures to different low-toxicity chemicals.

We found four organophosphates as active ingredients in the pesticides: chlorpyrifos, diazinon, dichlorvos, and EPN. Organophosphate pesticides are the leading cause of acute pesticide poisoning among adults (14). The effects of low-level, long-term exposure to organophosphate pesticides for adults and children have not been established. Nevertheless, there is evidence to suggest that significant health problems may occur from exposure (16). Given that organophosphate pesticides currently are used in many different settings, including in agriculture and in the home, the potential for multiple exposures is high.

Two issues raised in other studies that we begin to address in this survey are proper storage techniques and disposal methods of the household pesticides. In regards to storage precautions, the fact that fewer than $40 \%$ of the pesticide products were kept in a locked storage area is reason for concern. In addition, of those not kept locked away, $42 \%$ were stored less than four feet $(1.22 \mathrm{~m})$ from the ground. Because children often open and explore unlocked cupboards, more caution should be taken to prevent potential 
TABLE 3. Active ingredients found in the pesticides, household pesticide survey, Arizona, 1999a

\begin{tabular}{|c|c|c|}
\hline Active ingredient & $\begin{array}{c}\text { Frequency of } \\
\text { occurrence }^{\mathrm{a}}\end{array}$ & $\begin{array}{c}\text { Toxicity } \\
\text { class }^{b}\end{array}$ \\
\hline Technical piperonyl butoxide & 34 & Class IV \\
\hline Pyrethrins & 24 & Class III \\
\hline Permethrin & 18 & Class III \\
\hline d-cis, trans allethrin & 17 & Class II \\
\hline Diazinon & 16 & Class III \\
\hline Boric acid & 13 & NA \\
\hline n-Octyl bicycloheptenedicarboximide & 10 & NA \\
\hline Brodifacoum & 9 & Class I \\
\hline Bifenthrin & 8 & Class II \\
\hline Chlorpyrifos & 8 & Class III \\
\hline Phenothrin & 7 & Class IV \\
\hline Tralomethrin & 7 & Class I \\
\hline Tetramethrin & 7 & Class IV \\
\hline Petroleum distillate & 6 & NA \\
\hline Fenvalerate & 4 & Class II \\
\hline Dichlorvos/DDVP & 3 & Class I \\
\hline Propoxur & 3 & Class II \\
\hline Cyfluthrin & 2 & Class II \\
\hline Glyphosate & 2 & Class II \\
\hline Hydramethylnon & 2 & Class III \\
\hline Isopropylamine salt & 2 & NA \\
\hline Abamectin & 1 & Class II \\
\hline Acephate & 1 & Class III \\
\hline Bromethalin & 1 & Class II \\
\hline Carbaryl & 1 & Class III \\
\hline Chlordane & 1 & Class II \\
\hline Cypermethrin & 1 & Class III \\
\hline Diquat dibromide & 1 & Class II \\
\hline EPN & 1 & Class I \\
\hline Fluazifop-butyl & 1 & Class II \\
\hline Methyl nonyl ketone & 1 & Class IV \\
\hline Naphthalene & 1 & Class IV \\
\hline Oil of citronella & 1 & NA \\
\hline Prallethrin & 1 & Class III \\
\hline Resmethrin & 1 & Class III \\
\hline Triforine & 1 & Class I \\
\hline Xylene & 1 & Class II \\
\hline
\end{tabular}

easy access to many of these toxic chemicals. Additionally, over $40 \%$ of pesticides were not in child-resistant containers, creating another potentially significant threat to child safety.

Concerning pesticide disposal, for each pesticide product that the respondents presented, we asked how they would dispose of it when they were done with the product. Responses were open ended, and we recorded them using the respondents' own words. Respondents indicated that nearly $90 \%$ off all the pesticide products would just be thrown away. They listed only $7 \%$ of the pesticides that they would carefully dispose of, either by wrapping the product in paper and putting it in another bag before throwing it away or by using some other method. This finding raises additional questions about appropriate hazardous waste management.

While some general information was collected, this study did not gather data specific to lawn care and pesticide application. However, due to the number of respondents acknowledging professional applicators, we can infer that such chemicals were applied. The use of these pesticides can be a particular problem for children, who not only come in contact with these pesticides while playing outside but also track them inside (6). This is an area that deserves further attention if we are to fully understand the pesticide exposure risk for children.

Finally, of particular concern were seven households that reported using the "Miraculous Insecticide Chalk," a product from China. This is a product that many of the health workers talked about and used themselves, but is currently banned by the EPA for sale and use within the United States. All seven households said they purchased the product in the United States, with most of them saying they purchased it at a neighborhood store that specializes in Chinese products. This product comes in a package with primarily Chinese writing. Warnings issued by the EPA mentioned that the manufacturer often changes formula from one batch to the next, so the active ingredients cannot be ascertained and monitored. The exposure risk is ill defined not only because of lack of knowledge of the contents of the product, but also because the product is sold in the form of chalk sticks that resemble the nontoxic chalks that children often play with, so there is increased risk that the product will be mistaken for a child's toy.

This survey is one of the few studies that has specifically examined household pesticide use and the possibility that children will be exposed to the pesticides. Because of unique issues related to their growth and development, children may be at greater physiological risk from pesticides than adults are (16). In addition, multiple routes of exposure may affect children. For instance, children may be exposed outdoors while playing, indoors in schools and homes, and through their diets. Although each exposure may be individually small, the additive effects may be substantial (3).

The goal of this study was to begin to characterize routes of childhood exposure to pesticides in the home. This exploratory survey shows that household pesticides are an issue that deserves further research. Exposure risks from household pesticides in general have not been seriously examined by 
the public health community, and it will be important to include demographically diverse populations in future studies to appropriately define exposure. All avenues of pesticide exposure should continue to be investigated in order to fully evaluate childhood exposures. Understanding household pesticide use and developing a model of exposure will help in this process. Profiles of the use, storage, and disposal of products will also guide the development of effective education and poison prevention programs aimed at parents and children in the community.

\section{REFERENCES}

1. Lang L. Are pesticides a problem? Environ Health Perspect 1993;101:578-583.

2. Goldman LR. Children-unique and vulnerable: environmental risks facing children and recommendations for response. Environ Health Perspect 1995;103(Suppl 6):13-18.

3. Reigart JR. Pesticides and children. Pediatr Ann 1995;24:663-668.

4. United States, Environmental Protection Agency, Office of Children's Health and Protection. Health effects of pesticides. In: The EPA children's environmental health yearbook. Washington, D.C.: EPA, Office of Children's Health and Protection; 1998. pp. 83-104.

5. Zahm SH, Ward MH, Blair A. Pesticides and cancer. Occup Med 1997;25:146-157.

6. Simcox NJ, Fenske RA, Wolz SA, Lee IC, Kalman DA. Pesticides in household dust and soil: exposure pathways for children of agricultural families. Environ Health Perspect 1995;103:1126-1134. demiol 2000;10(2):159-167.
7. Thomas RD. Age-specific carcinogenesis: environmental exposure and susceptibility. Environ Health Perspect 1995;103(Suppl 6): $45-48$.

8. United States, Environmental Protection Agency. National Household Pesticide Usage Study, 1976-1977. Final report. Washington, D.C.: EPA, Office of Pesticide Programs; 1980.

9. Research Triangle Institute. National Home and Garden Pesticide Use Survey. Washington, D.C.: Environmental Protection Agency, Office of Pesticides and Toxic Substances; 1992.

10. Adgate JL, Kukowski A, Stroebel C, Shubat PJ, Morrell S, Quackenboss JJ, et al. Pesticide storage and use patterns in Minnesota households with children. J Expo Anal Environ Epi-

11. Davis JR, Brownson RC, Garcia R. Family pesticide use in the home, garden, orchard and yard. Arch Environ Contam Toxicol 1992;22: 260-266.
Acknowledgments. We would like to thank the following organizations for their support: Southeast Arizona Area Health Education Center (SEAHEC), Cochise County Health Department, Agua Prieta/Douglas Binational Health Council, Compañeros, and Douglas High School.
12. Savage EP, Keefe TJ. Household pesticide usage in the U.S. Arch Environ Health 1981; 36:304-309.

13. Farm Chemicals Handbook. Meister Publishing Company, Willoughby, Ohio, United States of America; 1998.

14. Reigart JR, Roberts JR. Recognition and management of pesticide poisonings, 5th ed. Washington, D.C.: United States, Environmental Protection Agency; 1999.

15. Parsons BJ, Day LM, Ozanne-Smith J, Dobbin M. Rodenticide poisoning among children. Aust N Z J Pub Health 1996;20:488-492.

16. Moses M, Johnson ES, Anger WK, Burse VW, Horstman SW, Jackson RJ, et al. Equity in environmental health: research issues and needs. Tox Ind Health 1993;9:914-959.

Manuscript received on 6 April 2000. Revised version accepted for publication on 11 November 2000.

RESUMEN Objetivos. Dado que se sabe muy poco acerca de los efectos del uso doméstico de pesticidas sobre la salud de los niños, los autores realizaron una encuesta con el fin de identificar los pesticidas usados en los hogares y averiguar dónde se usan y almacenan, y cuáles son los métodos utilizados para su eliminación.

Encuesta sobre el uso de pesticidas en el hogar

Métodos. En la primavera de 1999 se realizó una encuesta en una comunidad del estado de Arizona, Estados Unidos de América, fronteriza con México. Para poder participar en la encuesta, en los hogares se tenía que haber usado un pesticida en los 6 meses anteriores y tenía que residir al menos un niño menor de 10 años. Se obtuvo información general sobre el uso, almacenamiento y eliminación de pesticidas, además de información específica sobre cada uno de los pesticidas que se estaban usando o almacenado actualmente en la casa.

Resultados. En los 107 hogares encuestados se encontraron 148 productos pesticidas (media de 1,4 por hogar). La mitad de los pesticidas se guardaban a menos de 1,22 $\mathrm{m}$ del suelo, al alcance de los niños, y $70 \%$ se guardaban dentro de la casa, sobre todo en la cocina. La cocina era también el lugar donde más se usaban los pesticidas (69\% de los encuestados decían haber usado ahí al menos un pesticida).

Conclusiones. Se concluye que es importante seguir investigando todas las vías de exposición a los pesticidas para poder analizar la exposición infantil, proceso al que contribuirán el conocimiento sobre el uso doméstico de los pesticidas y el desarrollo de un modelo de exposición. Las características del uso, almacenamiento y eliminación de los pesticidas también servirán de guía para el desarrollo de programas comunitarios eficaces de educación y prevención de las intoxicaciones por estos productos. 